\title{
Highly Sensitive Visual Detection of Copper lons Based on the Shape-Dependent LSPR Spectroscopy of Gold Nanorods
}

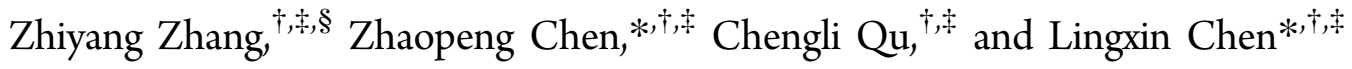

${ }^{\dagger}$ Key Laboratory of Coastal Environmental Processes and Ecological Remediation, Yantai Institute of Coastal Zone Research (YIC), Chinese Academy of Sciences(CAS) and ${ }^{\ddagger}$ Shandong Provincial Key Laboratory of Coastal Environmental Processes, YICCAS, Yantai Shandong 264003, P. R. China

${ }^{\S}$ University of Chinese Academy of Sciences, Beijing 100049, China

\section{Supporting Information}

ABSTRACT: We have developed a novel approach to the rapid visual detection of $\mathrm{Cu}^{2+}$ in natural samples based on the copper-mediated leaching of gold nanorods (GNRs). In the presence of hexadecyltrimethylammonium bromide, which can reduce the redox potential of $\mathrm{Au}(\mathrm{I}) /$ $\mathrm{Au}$, the GNRs are catalytically etched by $\mathrm{Cu}^{2+}$ preferentially along the longitudinal direction. And as a result, the localized surface plasmon resonance extinction peak shifts to short wavelength, accompanied by a color change from blue to red. The leaching mechanism has been carefully discussed in a series of control experiments. Under optimal conditions, this sensor exhibits good sensitivity $(\mathrm{LOD}=0.5 \mathrm{nM})$. Most importantly, the approach is highlighted by its high selectivity for and tolerance of interference, which enables the sensor to detect $\mathrm{Cu}^{2+}$ directly in a complex matrix, especially in seawater. Moreover, such a nanoparticle-based sensor is also successfully applied to test paper for the visual detection of $\mathrm{Cu}^{2+}$.

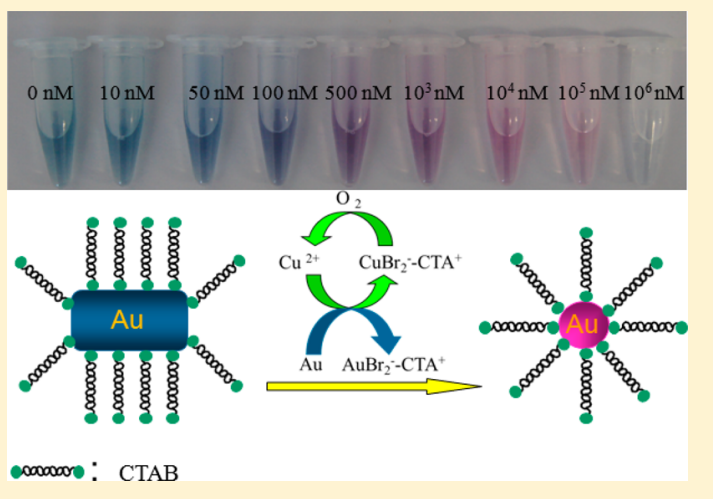

\section{INTRODUCTION}

Since the exposure of the Minamata event in the 1950s, contamination by heavy metals has aroused extensive public concern. The risk of such pollutants, even at "invisible" trace levels in the environment, is that they can be progressively concentrated through the food chain and present a threat to human health. ${ }^{1}$ Among heavy metals, despite its less-significant toxicity, copper has become a widely distributed pollutant in natural water as a result of the dumping of electronic trash and mining residues. The rapid onsite monitoring of $\mathrm{Cu}^{2+}$ is thereby emerging as an important analytic issue. ${ }^{2}$ However, the strong dependence of developed methods on instruments (AAS, AES, ICP-MS, etc.) prevents them from being used in outsidelaboratory applications. Such methods would also be affected by the complex matrix of certain natural waters (e.g., the matrix effects of seawater on ICP-MS ${ }^{3}$ and the interference of organics in anodic/cathodic stripping voltammetry ${ }^{4-6}$ ). The development of a portable but highly sensitive and selective method is thus urgently needed. To realize this purpose, many quantumdot-based fluorescent probes have been designed for $\mathrm{Cu}^{2+}$. ${ }^{-11}$ Such probes, compared to traditional organic probes, yield better sensitivity and selectivity but suffer from the interference of the sample matrix and the time-consuming process of the preparation of these functionalized quantum dots. A visual method based on the $\mathrm{Cu}^{+}$-dependent click reaction, ${ }^{2}$ showing high selectivity and tolerance to interference, has a relative high detection limit $(3.0 \mu \mathrm{M})$, which limits its application in most cases. Colorimetric probes based on target-inducing nanoparticle aggregation, compared to traditional chromogenic reagent-based methods, have proven to be more sensitive. These probes still encounter difficulties in sensing $\mathrm{Cu}^{2+}$ in complex matrixes because of the autoaggregation in water samples. ${ }^{12-15}$

Recently, a promising new strategy for sensing metal ions $\left(\mathrm{Pb}^{2+}\right)$ based on the catalytic etching of gold nanoparticles was first developed by Chen et al. ${ }^{16}$ The formation of a PbAu alloy decreased the redox potential of $\mathrm{Au}(\mathrm{I}) / \mathrm{Au}(0)$. In the presence of thiosulfate and mercaptoethanol, gold nanoparticles were oxidized by dissolved oxygen to produce $\mathrm{Au}(\mathrm{I})$. The wine-red colloidal gold was therefore bleached. Thereafter, our group developed similar methods for sensing $\mathrm{Cu}(\mathrm{II}) .{ }^{17,18}$ With the presence of thiosulfate, gold or silver nanoparticles were oxidized by $\mathrm{Cu}(\mathrm{II})$ to produce $\mathrm{Au}(\mathrm{I})$ or $\mathrm{Ag}(\mathrm{I})$ and $\mathrm{Cu}(\mathrm{I})$. The latter was then oxidized by dissolved oxygen, and $\mathrm{Cu}$ (II) was regenerated. The circle also led to the bleaching of colloidal gold or silver. Although these methods are sensitive and can be applied to the sensing of $\mathrm{Cu}(\mathrm{II})$ in tap water and drinking water, the low stability of thiosulfate-stabilized nanoparticles limited their application in complex matrixes. For example, high salt in seawater would lead to the aggregation of these nanoparticles.

In this work, using cetyltrimethylammonium bromide (CTAB)-stabilized gold nanorods (GNRs), the color of which is dependent on the aspect ratio, ${ }^{19,20}$ we have proposed a simple

Received: January 9, 2014

Revised: $\quad$ March 9, 2014

Published: March 11, 2014 
and sensitive visual sensor for $\mathrm{Cu}^{2+}$ based on the catalytic etching of GNRs. In this system, CTAB acts not only as a stabilizer but also as an ion-association reagent. As an association reagent, $\mathrm{CTAB}$ reduces the redox potential of $\mathrm{Au}(\mathrm{I}) / \mathrm{Au}(0)$, allowing GNRs to be oxidized by $\mathrm{Cu}^{2+}$. Additionally, the high binding force between the amino group of $\mathrm{CTAB}$ and gold could keep GNRs stable in a complex matrix. Thus a visual sensor can be used for the sensing of $\mathrm{Cu}^{2+}$ in a complex matrix, such as lake water, digested shellfish samples, and especially seawater.

\section{EXPERIMENTAL SECTION}

Chemicals and Apparatus. Hydrogen tetrachloroaurate(III) dehydrate, sodium borohydride, ascorbic acid, hydrochloric acid, silver nitrate, cetyltrimethylammonium bromide (CTAB), and $\mathrm{CuSO}_{4}$ were obtained from Sinopharm Chemical Reagent (China). All other chemicals were analytical reagent grade or better. Solutions were prepared with deionized water (18.2 $\mathrm{M} \Omega$, Pall Cascada). Filter paper (Supor 450, $0.45 \mu \mathrm{m}$ ) was obtained from the Pull Corporation of America.

Transmission electron microscopy (TEM) analyses were performed on a JEM-1230 electron microscope (Japan) operating at $100 \mathrm{kV}$. Extinction spectra were recorded on a Thermo Scientific NanoDrop 2000/2000C spectrophotometer.

Preparation of Gold Nanorods. Gold nanorods with different aspects (length/width ratio) were synthesized according to a modified method by changing the amount of $\mathrm{AgNO}_{3}{ }^{21}$ The obtained gold nanorods were centrifuged twice at $8000 \mathrm{rpm}$ for $15 \mathrm{~min}$ to remove excess ascorbic acid that would inhibit the sensitivity of the proposed probe (Supporting Information, Figure S1). The obtained soft sediment was then resuspended in deionized water. Finally, a different amount of $\mathrm{CTAB}$ was added to the gold nanorod solution.

Procedure for Sensing $\mathrm{Cu}^{2+}$. The prepared gold nanorods (200 $\mu \mathrm{L})$ were added to a hydrogen bromide-adjusted buffer solution (800 $\mu \mathrm{L}, 0.5 \mathrm{M})$ containing different concentrations of $\mathrm{Cu}^{2+}$ ions. The final concentration of gold nanorods was calculated to be about $0.33 \mathrm{nM}^{22}$ After incubation at $75{ }^{\circ} \mathrm{C}$ for $20 \mathrm{~min}$, the resulting solution was then subjected to UV-vis spectroscopic measurements.

\section{RESULTS AND DISCUSSION}

Scheme 1 presents the sensing mechanism for the detection of $\mathrm{Cu}^{2+}$. In the absence of $\mathrm{Cu}^{2+}, \mathrm{CTAB}$-stabilized GNRs were

Scheme 1. Schematic Illustration of the Sensing Mechanism for the Detection of $\mathrm{Cu}^{2+}$
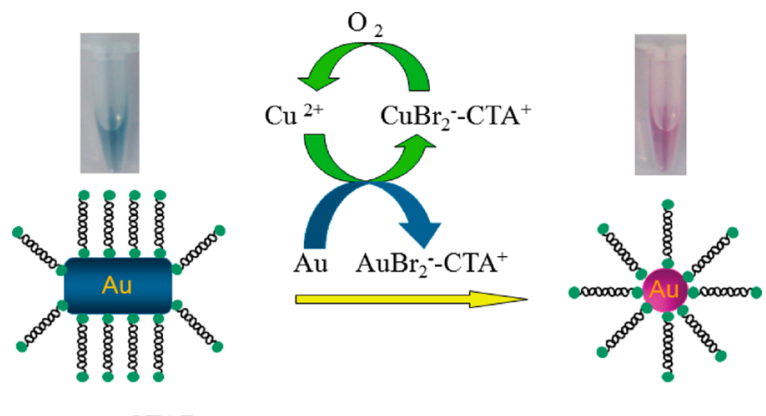

(

etched slowly by dissolved oxygen in hydrobromic acid solution $^{23}$ and the GNR solution remained blue during the incubation process $(20 \mathrm{~min})$. The negligible color change corresponds well to the slight change in the localized surface plasmon resonance (LSPR) extinction spectrum of GNRs (Supporting Information, Figure S2). With addition of $\mathrm{Cu}^{2+}$, the GNRs were catalytically etched along the longitudinal direction (Supporting Information, Figure S3). The etching of
GNRs resulted in the decrease of aspect ratio of GNRs as shown in the TEM images (Figure 1) and the aspect ratio distributions

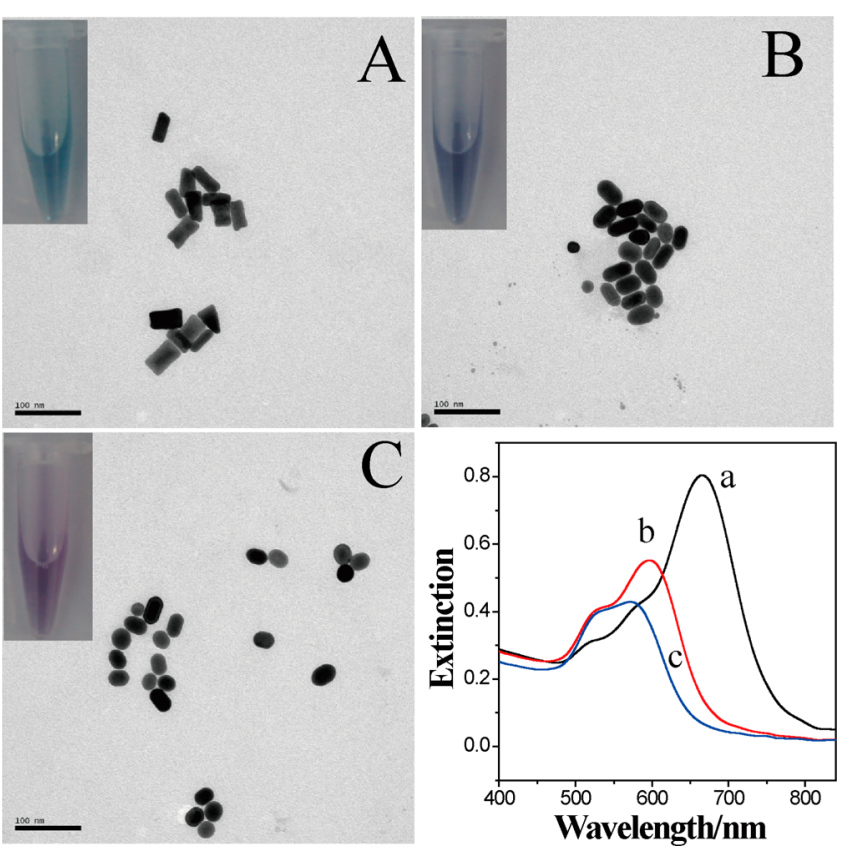

Figure 1. TEM images and extinction spectra of GNRs after incubation with $0(\mathrm{~A}, \mathrm{a}), 1.0(\mathrm{~B}, \mathrm{~b})$, and $10 \mu \mathrm{M} \mathrm{Cu}^{2+}(\mathrm{C}, \mathrm{c})$ in $0.5 \mathrm{M} \mathrm{HBr}$ at $75^{\circ} \mathrm{C}$ for $20 \mathrm{~min}$.

(Figure S3, Supporting Information). The preferential shortening along the longitudinal direction can be attributed to less surface passivation and/or higher reaction activities at the tips of the gold nanorods. ${ }^{23-25}$ The anisotropic etching led to the blue shift of the LSPR extinction spectrum of GNRs (Figure 1), accompanied by a color change from blue to red and even to colorless with the increase in $\mathrm{Cu}^{2+}$, providing a visual method for sensing $\mathrm{Cu}^{2+}$ (Scheme 1).

To explore the etching mechanism, we added a high concentration of $\mathrm{Cu}^{2+}(2 \mathrm{mM})$ to the colloidal gold in the presence of $0.5 \mathrm{M} \mathrm{HBr}$, and the solution was incubated at room temperature for several minutes. The color of the mixture changed to colorless within $5 \mathrm{~min}$ (Figure S4, Supporting Information). This indicated that $\mathrm{Au}$ was transformed to $\mathrm{Au}(\mathrm{I})$ instead of $\mathrm{Au}$ (III). In addition, a new absorption band at around $280 \mathrm{~nm}$ was immediately obtained as the colloid turned colorless. As the incubation progressed, the absorption at $280 \mathrm{~nm}$ decreased gradually with time, suggesting the formation of $\mathrm{Cu}(\mathrm{I})$ and the further transformation of $\mathrm{Cu}(\mathrm{I})$ to other species (Figure S5, Supporting Information). ${ }^{26}$

Judging from the redox potential of $\mathrm{AuBr}_{2}{ }^{-} / \mathrm{Au}(0.93 \mathrm{~V}$ vs the normal hydrogen electrode, $\mathrm{NHE})$ and $\mathrm{Cu}^{2+} / \mathrm{CuBr}_{2}^{+}(0.52 \mathrm{~V}$ vs $\mathrm{NHE})$, theoretically gold cannot be oxidized by $\mathrm{Cu}^{2+}$. The etching of GNRs by $\mathrm{Cu}^{2+}$ in this study, we think, should be related to the conjugation of $\mathrm{CTA}^{+}$with $\mathrm{CuBr}_{2}{ }^{+}$and $\mathrm{AuBr}_{2}{ }^{-}$. Figure $\mathrm{S} 6$ in the Supporting Information illustrates the effect of $\mathrm{CTAB}$ on the etching of wine-red gold nanoparticles $(13 \mathrm{~nm})$. Herein we used AuNPs to replace GNRs because the synthesis of AuNPs needs no introduction of CTAB. Prepared AuNPs were first stabilized by $0.4 \%$ tween- 20 in $0.5 \mathrm{HBr}$ solution. Without or with the addition of $\mathrm{Cu}^{2+}$, the color of the AuNP solutions remained wine red, and the extinction peak around $520 \mathrm{~nm}$ was not altered, indicating no etching of AuNPs occurred. Thereafter, 
2 mM CTAB was introduced, and the color changed to reddish with a decrease in the extinction peak at around $520 \mathrm{~nm}$. It was also observed that the etching rate would be improved with the increase in $\mathrm{CTAB}$ concentration. To confirm that the etching process was essentially affected by $\mathrm{CTA}^{+}$but not by increasing the $\mathrm{Br}^{-}$concentration, a control experiment was also conducted by replacing $\mathrm{CTAB}$ with $\mathrm{NaBr}$. As shown in Figure S7 in the Supporting Information, different concentrations of $\mathrm{NaBr}$ of less than $4 \mathrm{mM}$ had little effect on the etching of tween-20-stabilized gold nanoparticles.

In the presence of $\mathrm{CTA}^{+}$, the redox potential of $\mathrm{AuBr}_{2}{ }^{-}-$ $\mathrm{CTA}^{+} / \mathrm{Au}, E_{\mathrm{AuBr}_{2}{ }^{-}-\mathrm{CTA}^{+} / \mathrm{Au}}$ could decline to less than $0.2 \mathrm{~V}$ (vs

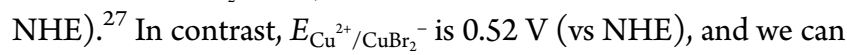
conclude that this value will be higher than $0.52 \mathrm{~V}$ (vs NHE) because $\mathrm{CuBr}_{2}{ }^{-}$can also conjugate with $\mathrm{CTA}^{+}$. Theoretically, $\mathrm{Au}$ can be oxidized by $\mathrm{Cu}^{2+}$ to produce $\mathrm{AuBr}_{2}{ }^{-}-\mathrm{CTA}^{+}$and $\mathrm{CuBr}_{2}{ }^{-}-$ $\mathrm{CTA}^{+}$. In addition, $E_{\mathrm{O}_{2} / \mathrm{H}_{2} \mathrm{O}}$ is about $1.20 \mathrm{~V}$ (vs NHE) in acid solution calculated according to the Nernst equation. Therefore, the following circle was thereby presumed for the continuous etching of GNRs:

$$
\begin{aligned}
& \mathrm{Au}+\mathrm{Cu}^{2+}+\mathrm{CTA}^{+}+\mathrm{Br}^{-} \\
& \rightarrow \mathrm{AuBr}_{2}{ }^{-}-\mathrm{CTA}^{+}+\mathrm{CuBr}_{2}{ }^{-}-\mathrm{CTA}^{+} \\
& \mathrm{CuBr}_{2}{ }^{-}-\mathrm{CTA}^{+}+\mathrm{O}_{2} \rightarrow \mathrm{Cu}^{2+}+\mathrm{H}_{2} \mathrm{O}+\mathrm{Br}^{-}+\mathrm{CTA}^{+}
\end{aligned}
$$

To test this assumption, several control experiments were conducted from different aspects. Figure 2 describes the effect of

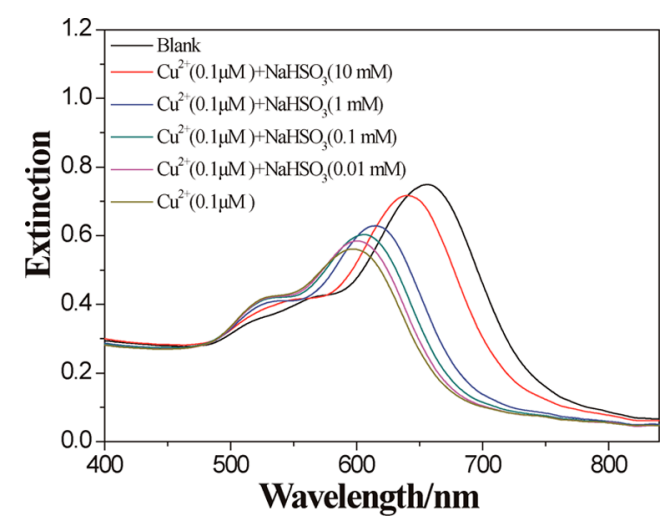

Figure 2. Extinction spectra of GNRs after incubation with $0.1 \mu \mathrm{M} \mathrm{Cu}^{2+}$ in $0.5 \mathrm{M} \mathrm{HBr}$ after removing dissolved oxygen by the addition of different concentrations of $\mathrm{NaHSO}_{3}$ at $75^{\circ} \mathrm{C}$ for $20 \mathrm{~min}$.

dissolved oxygen on the etching process. It was observed that, with the preremoval of dissolved oxygen by the addition of $\mathrm{NaHSO}_{3}\left(2 \mathrm{SO}_{3}{ }^{2-}+\mathrm{O}_{2} \rightarrow 2 \mathrm{SO}_{4}{ }^{2-}\right)$, the etching of GNRs was inhibited by the less-significant blue shift. Moreover, the etching rate decreased with the increasing $\mathrm{NaHSO}_{3}$ concentration. These results indicated that dissolved oxygen participated in the etching reaction and may oxidize $\mathrm{CuBr}_{2}{ }^{-}-\mathrm{CTA}^{+}$to $\mathrm{Cu}^{2+}$.

Thereafter, an aliquot of $0.1 \mathrm{M} \mathrm{CuBr}$ in $\mathrm{HBr}$ solution was mixed with an equal volume of $0.1 \mathrm{M} \mathrm{CTAB}$. The mixture immediately changed to a milky-white emulsion, suggesting the formation of $\mathrm{CuBr}_{2}{ }^{-}-\mathrm{CTA}^{+}$as an ion-association complex. The emulsion was then incubated at $75{ }^{\circ} \mathrm{C}$ for $5 \mathrm{~min}$, and a clear solution was obtained. However, the process would not be reversibly converted when the temperature decreased. This phenomenon should be due to the oxidation of $\mathrm{CuBr}_{2}{ }^{-}-\mathrm{CTA}^{+}$ by dissolved oxygen, which converted barely soluble $\mathrm{CuBr}_{2}{ }^{-}-$
$\mathrm{CTA}^{+}$to highly soluble $\mathrm{Cu}^{2+}$. Figure $\mathrm{S} 8$ in the Supporting Information illustrates the absorption spectrum of $1 \mathrm{mM}$ $\mathrm{CuBr}_{2}{ }^{-}-\mathrm{CTA}^{+}$after incubation at room temperature for different times (curves $\mathrm{a}-\mathrm{c}$ ). The absorption at around 280 $\mathrm{nm}$ was observed to decrease gradually with the increase in incubation time and finally showed no difference to that of $1 \mathrm{mM}$ $\mathrm{Cu}^{2+}$ in the presence of CTAB (curve $\mathrm{d}$ ). Thus, the oxidation of $\mathrm{CuBr}_{2}{ }^{-}-\mathrm{CTA}^{+}$by dissolved oxygen could also be verified.

Because $\mathrm{CuBr}_{2}{ }^{-}-\mathrm{CTA}^{+}$could be oxidized by dissolved oxygen, it is reasonable to assume that $\mathrm{Cu}^{+}$would catalyze the etching of GNRs by dissolved oxygen in $\mathrm{HBr}$ solutions in the presence of CTAB. Figure S9 in the Supporting Information demonstrates the test results of such an assumption. A blue shift of the longitudinal LSPR extinction peak was observed. The blue shift appeared to be more significant with the increase in $\mathrm{CuBr}$. It can be concluded that the etching of GNRs by dissolved oxygen could also be accelerated by $\mathrm{Cu}^{+}$.

Inspired by the outstanding catalytic property of $\mathrm{Cu}^{2+}$ upon the etching of GNRs, a simple and practical sensor was used for the sensing of $\mathrm{Cu}^{2+}$ in a complex matrix. Several key factors, including the $\mathrm{CTAB}$ concentration, temperature, and time were optimized (Figures S10-S15, Supporting Information). Figure 3 shows the responses of the proposed sensors to different concentrations of $\mathrm{Cu}^{2+}$ under the optimal condition. The longitudinal LSPR extinction peak of GNRs were bleached and shifted to short wavelength gradually with increasing $\mathrm{Cu}^{2+}$ concentration (Figure 3A,B). Two different linear relationships, one between the peak shift and $\mathrm{Cu}^{2+}$ concentrations (1.0 to 20 $\mathrm{nM}$, Figure 3C) and the other between the peak shift and logarithm of $\mathrm{Cu}^{2+}$ concentrations (20 to $10^{5} \mathrm{nM}$, Figure 3D), were respectively obtained. The detection limit was calculated to be $0.5 \mathrm{nM}$ according to the $S / N=3$ rule, which is lower than that of other nanoparticles and quantum-dot-based sensors, ${ }^{7-11,17,18,28}$ and is comparable to the results obtained by AAS, AES, ICPMS, and anodic/cathodic stripping voltammetry (Table 1). ${ }^{29-35}$ Digital photographs (Figure 3E) show that the color of the GNR solutions changed from blue to red and even to colorless with increasing $\mathrm{Cu}^{2+}$ content. The color change induced by $50 \mathrm{nM} \mathrm{Cu}^{2+}$ can be easily observed by the naked eye. Such a concentration is almost 3 orders of magnitude lower than the safety limit defined by WHO $(20 \mu \mathrm{M})$.

The specificity of the sensor toward $\mathrm{Cu}^{2+}$ was evaluated by examining the extinction spectra of GNRs in $\mathrm{HBr}$ solution in the presence of various other cations and anions, including $\mathrm{Li}^{+}, \mathrm{Na}^{+}$, $\mathrm{K}^{+}, \mathrm{Ca}^{2+}, \mathrm{Mg}^{2+}, \mathrm{Al}^{3+}, \mathrm{Zn}^{2+}, \mathrm{Fe}^{3+}, \mathrm{Pb}^{2+}, \mathrm{Hg}^{2+}, \mathrm{Ag}^{+}, \mathrm{Mn}^{2+}, \mathrm{Co}^{2+}$, $\mathrm{Ni}^{2+}, \mathrm{Cd}^{2+}, \mathrm{Cr}(\mathrm{VI}), \mathrm{NO}_{3}{ }^{-}, \mathrm{SO}_{4}{ }^{2-}, \mathrm{PO}_{4}{ }^{3-}$, and $\mathrm{NO}_{2}{ }^{-}$at a concentration of $1.0 \mu \mathrm{M}$ (Figure 4). It was found that the color and spectra of GNRs changed very little with the addition of those ions. However, the addition of $0.1 \mu \mathrm{M} \mathrm{Cu}^{2+}$ caused the solution color to change from blue to blue-gray, accompanied by a significant peak shift in the longitudinal LSPR extinction. A greater concentration of $\mathrm{Cu}^{2+}(1.0 \mu \mathrm{M})$ led to a more obvious color change and more peak shifts. The interference of other ions was also evaluated by mixing the ions mentioned above (each at a concentration of $1.0 \mu \mathrm{M}$ ) and GNRs in $\mathrm{HBr}$ solution in the presence and absence of $\mathrm{Cu}^{2+}$. The results showed that the presence of those ions had negligible effects on the detection of $\mathrm{Cu}^{2+}$. For these reasons, we concluded that the probe displayed excellent selectivity toward $\mathrm{Cu}^{2+}$.

To test the applicability of the proposed probe for $\mathrm{Cu}^{2+}$ detection in real samples, several samples including lake water (Sanyuan lake, Yantai university), seawater (certified seawater purchased from National Research Council Canada), and 


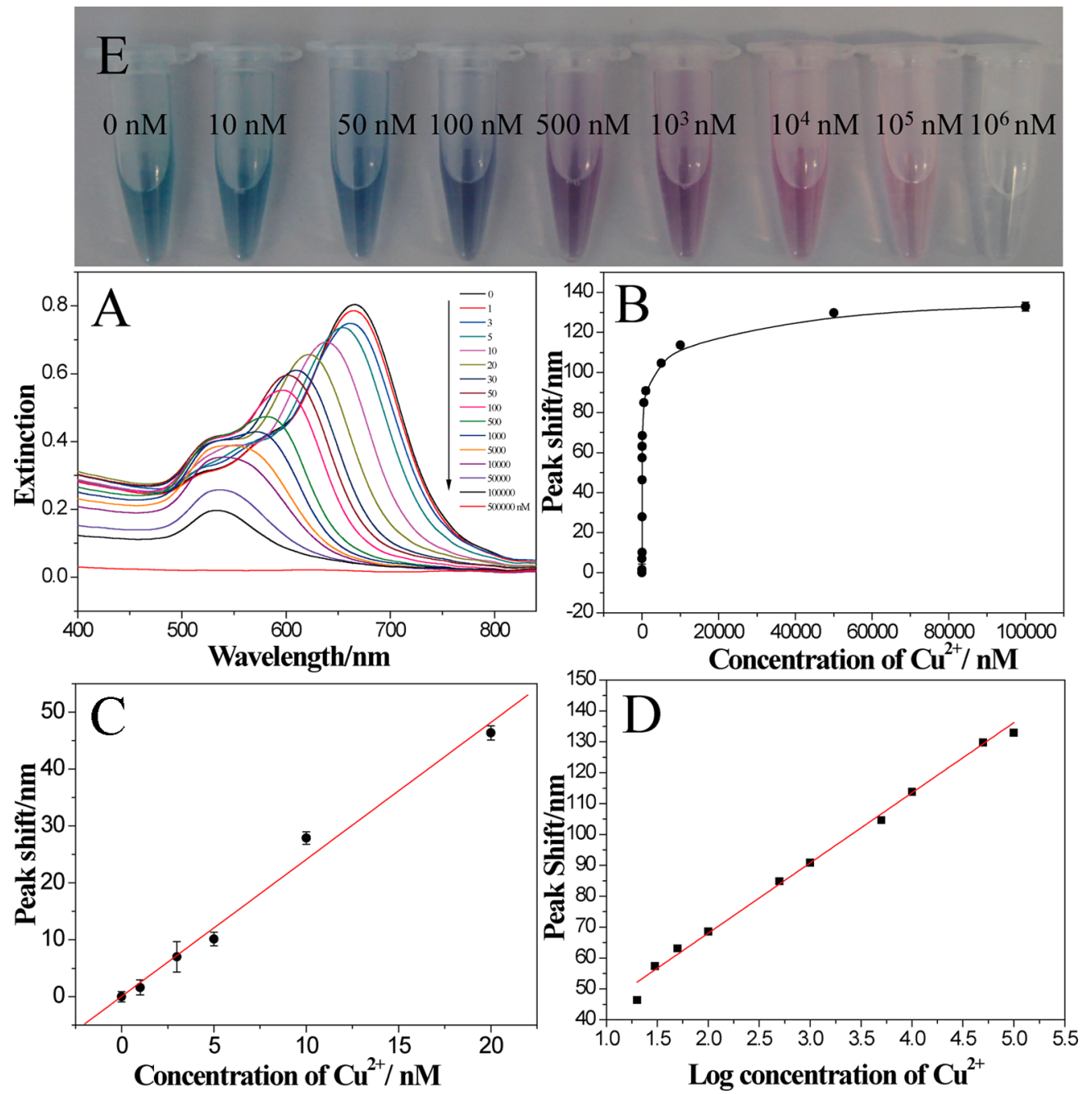

Figure 3. Extinction spectra (A), longitudinal LSPR extinction peak shifts (B-D), and color changes (E) of GNRs after incubation with different concentrations of $\mathrm{Cu}^{2+}$.

Table 1. Comparison of the Performance of Different Analytical Methods for the Detection of $\mathrm{Cu}^{2+}$

\begin{tabular}{|c|c|c|c|}
\hline material/method & detection limit & sample & ref \\
\hline hybrid material composed of $\mathrm{SiO}_{2}, \mathrm{Al}_{2} \mathrm{O}_{3}$, and $\mathrm{TiO}_{2} / \mathrm{AAS}$ & $0.5 \mathrm{ppb}$ & tap and mineral water and ethanol fuel & 29 \\
\hline Amberlite XAD-2-functionalized 3-(2-nitropheny1)-1H-1,2,4-triazole-5(4H)-thione/AES & $0.18 \mathrm{ppt}$ & river water and vegetables & 30 \\
\hline chitosan-grafted multiwalled carbon nanotubes/ICPMS & $3.5 \mathrm{ppt}$ & $\begin{array}{l}\text { herring, spinach, and river and tap } \\
\text { water }\end{array}$ & 31 \\
\hline gold nanoelectrode ensembles/voltammetry & subppb & & 32 \\
\hline gold microwire electrode/voltammetry & $25 \mathrm{pM}$ & coastal water & 33 \\
\hline gold cysteamine self-assembled monolayer functionalized with salicylaldehyde/voltammetry & $75 \mathrm{pM}$ & blood serum and synthetic sample & 34 \\
\hline cysteine-modified gold electrode/voltammetry & $0.39 \mathrm{nM}$ & river and seawater & 35 \\
\hline 16-mercaptohexadecanoic acid-capped CdSe QDs/fluorescence & $5 \mathrm{nM}$ & physiological fluids & 8 \\
\hline polyamine-functionalized carbon quantum dots/fluorescence & $6 \mathrm{nM}$ & river water & 7 \\
\hline polyethylenimine-protected silver nanoclusters/fluorescence & $10 \mathrm{nM}$ & river, lake, tap, and spring water & 11 \\
\hline meso-2,3-dimercaptosuccinic acid DMSA-capped CdTe QDs/visual detection & $10 \mathrm{nM}$ & synthetic sample & 9 \\
\hline $\begin{array}{l}\text { (sodium poly(2-(4-methyl-3-thienyloxy)propanesulfonate/click-reaction-based visual } \\
\text { detection }\end{array}$ & $3 \mu \mathrm{M}$ & tap and lake water & 2 \\
\hline $\begin{array}{l}\text { thiosulfate-stabilized } \mathrm{Ag} / \mathrm{Au} \text { nanoparticles/visual detection/visual and spectrophotometric } \\
\text { detection }\end{array}$ & $\sim 50 \mathrm{nM} / 1 \mathrm{nM}$ & tap and pond water & 17 \\
\hline CTAB-stabilized gold nanoparticles/visual and spectrophotometric detection & $40 \mathrm{nM} / 5.0 \mathrm{nM}$ & shellfish, tap and drinking water & 18 \\
\hline azide- and alkyne-functionalized gold nanoparticles/click-reaction-based visual detection & $50 \mu \mathrm{M}$ & & 28 \\
\hline CTAB-stabilized gold nanorods/visual and spectrophotometric detection & $50 \mathrm{nM} / 0.5 \mathrm{nM}$ & shellfish, lake and seawater & this $\mathrm{v}$ \\
\hline
\end{tabular}

digested shellfish samples were tested using this probe. Table 2 shows the detection results using the proposed probe. The detection results are consistent with the certified concentration, spiked concentrations, and ICPMS results. It is particularly noteworthy that our sensor yields excellent tolerance to the high salinity of seawater without any aggregation during the etching 


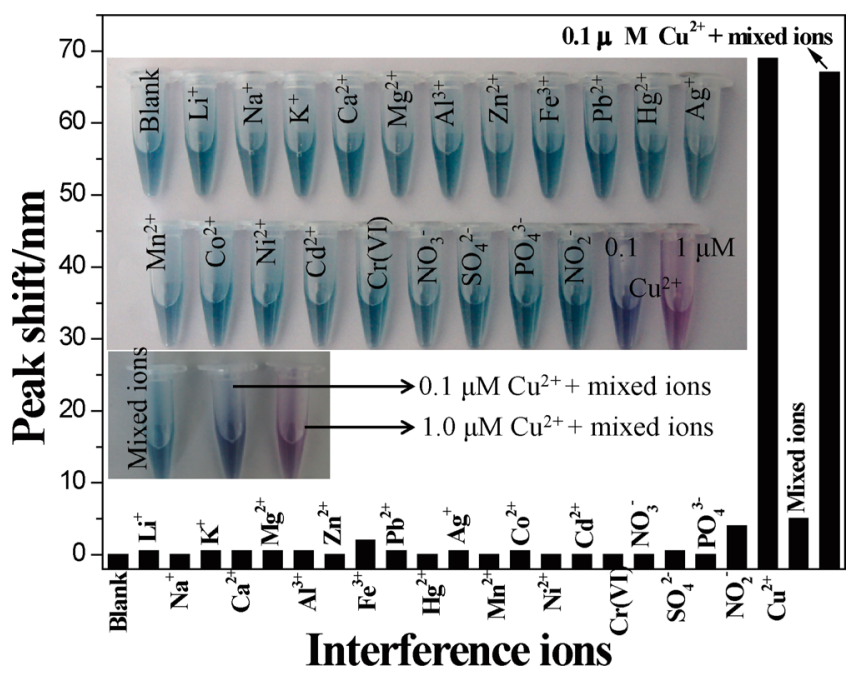

Figure 4. LSPR extinction peak shift and color change (photograph inset) of GNRs after incubation with various environmental ions. [ $\left.\mathrm{Cu}^{2+}\right]$ $=0.1 \mu \mathrm{M}$, [other ions] $=1.0 \mu \mathrm{M}$.

Table 2. Determination Results in Real Samples by the Proposed Method

\begin{tabular}{cccccc}
\hline \multicolumn{2}{c}{ sample } & $\begin{array}{c}\text { certified or } \\
\text { spiked } \\
\text { concentration }\end{array}$ & detected & $\begin{array}{c}\text { recovery } \\
(\%)\end{array}$ & $\begin{array}{c}\text { relative } \\
\text { error } \\
(\%)\end{array}$ \\
digested & sample 1 & $8.6 \mu \mathrm{M}^{a}$ & $9.2 \mu \mathrm{M}$ & 106.9 & 4.1 \\
shellfish & sample 2 & $14.4 \mu \mathrm{M}^{a}$ & $12.6 \mu \mathrm{M}$ & 88.2 & 12.3 \\
samples & sample 3 & $12.2 \mu \mathrm{M}^{a}$ & $14.7 \mu \mathrm{M}$ & 120.4 & 3.5 \\
& sample 4 & $14.3 \mu \mathrm{M}^{a}$ & $12.6 \mu \mathrm{M}$ & 88.1 & 4.1 \\
& sample 5 & $10.6 \mu \mathrm{M}^{a}$ & $11.9 \mu \mathrm{M}$ & 111.5 & 3.5 \\
lake water & sample 1 & $0.5 \mu \mathrm{M}^{b}$ & $5.9 \mu \mathrm{M}$ & 119.1 & 11.1 \\
& sample 2 & $1.0 \mu \mathrm{M}^{b}$ & $10.7 \mu \mathrm{M}$ & 107.3 & 6.5 \\
seawater & sample 3 & $1.5 \mu \mathrm{M}^{b}$ & $1.38 \mu \mathrm{M}$ & 91.7 & 4.1 \\
& sample 1 & $0.371 \mathrm{ppb}^{c}$ & $0.395 \mathrm{ppb}$ & 106.4 & 15.5 \\
& sample 2 & $5 \mathrm{ppb}^{b}$ & $4.63 \mathrm{ppb}$ & 92.6 & 4.3 \\
& sample 3 & $100 \mathrm{ppb}^{b}$ & $87.4 \mathrm{ppb}$ & 87.4 & 2.1
\end{tabular}

${ }^{a}$ ICPMS results. ${ }^{b}$ Spiked concentrations. ${ }^{c}$ Certified concentration.

process (Figures S16 and S17, Supporting Information), which is why this method can be used in seawater. For a long time, the detection of trace metals in seawater has been a forbidden subject for nanoparticles-based visual probes. Such results demonstrate that our probe could be a practical tool for the rapid on-site monitoring of $\mathrm{Cu}^{2+}$ (especially in seawater).

On the basis of the above efforts, a simple test paper was also preliminarily developed for the visual detection of $\mathrm{Cu}^{2+}$. Briefly, $5.0 \mu \mathrm{L}$ of a CTAB-stabilized GNR colloid was dropped onto a specific zone of filter papers (Supor 450, $0.45 \mu \mathrm{m}$, Pall Corporation, USA). The solution was thereafter evaporated in air sufficiently. The sensing zone was immersed in a $2 \mathrm{M} \mathrm{HBr}$ solution premixed with target or standard aqueous samples. After incubation at $75{ }^{\circ} \mathrm{C}$ for $20 \mathrm{~min}$, the color of each test zone was inspected and compared. The color turned red and even colorless gradually wit increasing $\mathrm{Cu}^{2+}$ content (Figure 5), which is obvious enough to the naked eye at a concentration of $100 \mathrm{nM}$. The recognizable limit of such a test paper, as tested by uninformed volunteers, was $100 \mathrm{nM}$ for $\mathrm{Cu}^{2+}$ with the naked eye. The designed test paper, as compared to other reports, is much simpler, more economical, and more practical for the detection of $\mathrm{Cu}^{2+}+36-38$

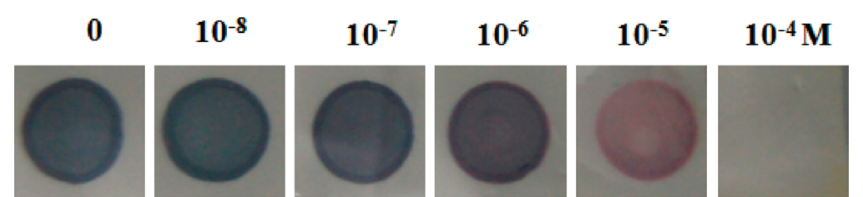

Figure 5. Photographs of the proposed test paper for the sensing of different concentrations of $\mathrm{Cu}^{2+}$.

\section{CONCLUSIONS}

We have developed a novel approach for the visual sensing of $\mathrm{Cu}^{2+}$ with high sensitivity and selectivity in aqueous media based on the catalytic etching of GNRs, which caused a change in the shape-dependent LSPR spectroscopy of GNRs. Compared to other sensors for the detection of $\mathrm{Cu}^{2+}$, our sensor shows a rapid response and sensitivity toward $\mathrm{Cu}^{2+}$, with a detectable range (50 $\mathrm{nM}-1.0 \mathrm{mM}$ ) over 5 orders of magnitude by the naked eye. To the best of our knowledge, the visual detection limit, $50 \mathrm{nM}$, is among the lowest reported for the detection of $\mathrm{Cu}^{2+}$. Importantly, this sensor is highlighted by its excellent selectivity and high tolerance to interference, which enables the sensor to detect $\mathrm{Cu}^{2+}$ directly in a complex matrix without complicated processes of sample pretreatment. Because the approach avoids the need for sophisticated equipment, the sensor promises to be a practical tool for the in situ monitoring of $\mathrm{Cu}^{2+}$. Moreover, such a nanoparticle-based sensor is applied to test paper for the detection $\mathrm{Cu}^{2+}$ with the naked eye. The test paper would be potentially used in the rapid detection of $\mathrm{Cu}^{2+}$ in real samples.

\section{ASSOCIATED CONTENT}

S Supporting Information

$\mathrm{UV}$-vis extinction/absorption spectra; photographs of HAu$\mathrm{Cl}_{4}(\mathrm{III}), \mathrm{Au}(\mathrm{I}), \mathrm{GNR}$ with different aspect ratios; and GNR distributions for the proposed proof of mechanism. This material is available free of charge via the Internet at http://pubs.acs.org.

\section{AUTHOR INFORMATION}

\section{Corresponding Authors}

*E-mail zhpchen@yic.ac.cn. Fax/phone: 086-535-2109133.

*E-mail lxchen@yic.ac.cn. Fax/phone: 086-535-2109130.

Notes

The authors declare no competing financial interest.

\section{ACKNOWLEDGMENTS}

This research was financially supported by the Department of Science and Technology of Shandong Province (BS2009DX006), the NSFC (No. 21275158), and the project sponsored by SRF for ROCS and the 100 Talents Program of the CAS.

\section{REFERENCES}

(1) Onyido, I.; Norris, A. R; Buncel, E. Biomolecule-mercury interactions: modalities of DNA base-mercury binding mechanisms. Remediation strategies. Chem. Rev. 2004, 104, 5911-5929.

(2) Yao, Z. Y.; Yang, Y. B.; Chen, X. L.; Hu, X. P.; Zhang, L.; Liu, L.; Zhao, Y. L.; Wu, H. C. Visual detection of copper(II) ions based on an anionic polythiophene derivative using click chemistry. Anal. Chem. 2013, 85, 5650-5653.

(3) Leonhard, P.; Pepelnik, R.; Prange, A.; Yamada, N.; Yamada, T. Analysis of diluted sea-water at the ng $\mathrm{L}^{-1}$ level using an ICP-MS with an octopole reaction cell. J. Anal. Atom. Spectrom. 2002, 17, 189-196.

(4) Turyan, I.; Mandler, D. Electrochemical determination of trace amounts of gold(III) by anodic-stripping voltammetry using a chemically-modified electrode. Anal. Chem. 1993, 65, 2089-2092. 
(5) Turyan, I.; Mandler, D. Selective determination of Cr(VI) by a selfassembled monolayer-based electrode. Anal. Chem. 1997, 69, 894-897.

(6) Turyan, I.; Mandler, D. Self-assembled monolayers in electroanalytical chemistry - application of $\omega$-mercaptocarboxylic acid monolayers for electrochemical determination of ultralow levels of cadmium(II). Anal. Chem. 1994, 66, 58-63.

(7) Dong, Y. Q.; Wang, R. X.; Li, G. L.; Chen, C. Q.; Chi, Y. W.; Chen, G. N. Polyamine-functionalized carbon quantum dots as fluorescent probes for selective and sensitive detection of copper ions. Anal. Chem. 2012, 84, 6220-6224.

(8) Chan, Y. H.; Chen, J. X.; Liu, Q. S.; Wark, S. E.; Son, D. H.; Batteas, J. D. Ultrasensitive copper(II) detection using plasmon-enhanced and photo-brightened luminescence of CdSe quantum dots. Anal. Chem. 2010, 82, 3671-3678.

(9) Wang, P.; Lei, J.; Su, M.; Liu, Y.; Hao, Q.; Ju, H. Highly efficient visual detection of trace copper(II) and protein by the quantum photoelectric effect. Anal. Chem. 2013, 85, 8735-8740.

(10) Yao, J. L.; Zhang, K.; Zhu, H. J.; Ma, F.; Sun, M. T.; Yu, H.; Sun, J.; Wang, S. H. Efficient ratiometric fluorescence probe based on dualemission quantum dots hybrid for on-site determination of copper ions. Anal. Chem. 2013, 85, 6461-6468.

(11) Yuan, Z.; Cai, N.; Du, Y.; He, Y.; Yeung, E. S. Sensitive and selective detection of copper ions with highly stable polyethyleneimineprotected silver nanoclusters. Anal. Chem. 2014, 86, 419-426.

(12) Weng, Z. Q.; Wang, H. B.; Vongsvivut, J.; Li, R. Q.; Glushenkov, A. M.; He, J.; Chen, Y.; Barrow, C. J.; Yang, W. R. Self-assembly of coresatellite gold nanoparticles for colorimetric detection of copper ions. Anal. Chim. Acta 2013, 803, 128-134.

(13) Guo, Y.; Wang, Z.; Qu, W.; Shao, H.; Jiang, X. Colorimetric detection of mercury, lead and copper ions simultaneously using protein-functionalized gold nanoparticles. Biosens. Bioelectron. 2011, 26, 4064-4069.

(14) Ye, S. Q.; Shi, X. H.; Gu, W.; Zhang, Y. X.; Xian, Y. Z. A colorimetric sensor based on catechol-terminated mixed self-assembled monolayers modified gold nanoparticles for ultrasensitive detections of copper ions. Analyst 2012, 137, 3365-3371.

(15) Yang, W. R.; Gooding, J. J.; He, Z. C.; Li, Q.; Chen, G. N. Fast colorimetric detection of copper ions using $\mathrm{L}$-cysteine functionalized gold nanoparticles. J. Nanosci. Nanotechnol. 2007, 7, 712-716.

(16) Chen, Y. Y.; Chang, H. T.; Shiang, Y. C.; Hung, Y. L.; Chiang, C. K.; Huang, C. C. Colorimetric assay for lead ions based on the leaching of gold nanoparticles. Anal. Chem. 2009, 81, 9433-9439.

(17) Lou, T.; Chen, L.; Chen, Z.; Wang, Y.; Chen, L.; Li, J. Colorimetric detection of trace copper ions based on catalytic leaching of silver-coated gold nanoparticles. ACS Appl. Mater. Interfaces 2011, 3, $4215-4220$.

(18) Liu, R.; Chen, Z.; Wang, S.; Qu, C.; Chen, L.; Wang, Z. Colorimetric sensing of copper(II) based on catalytic etching of gold nanoparticles. Talanta 2013, 112, 37-42.

(19) Perez-Juste, J.; Liz-Marzan, L. M.; Carnie, S.; Chan, D. Y. C.; Mulvaney, P. Electric-field-directed growth of gold nanorods in aqueous surfactant solutions. Adv. Funct. Mater. 2004, 14, 571-579.

(20) Chen, H.; Shao, L.; Li, Q.; Wang, J. Gold nanorods and their plasmonic properties. Chem. Soc. Rev. 2013, 42, 2679-2724.

(21) Sau, T. K.; Murphy, C. J. Seeded high yield synthesis of short Au nanorods in aqueous solution. Langmuir 2004, 20, 6414-6420.

(22) Orendorff, C. J.; Murphy, C. J. Quantitation of metal content in the silver-assisted growth of gold nanorods. J. Phys. Chem. B 2006, 110, 3990-3994.

(23) Tsung, C. K.; Kou, X. S.; Shi, Q. H.; Zhang, J. P.; Yeung, M. H.; Wang, J. F.; Stucky, G. D. Selective shortening of single-crystalline gold nanorods by mild oxidation. J. Am. Chem. Soc. 2006, 128, 5352-5353.

(24) Zou, R. X.; Guo, X.; Yang, J.; Li, D. D.; Peng, F.; Zhang, L.; Wang, H. J.; Yu, H. Selective etching of gold nanorods by ferric chloride at room temperature. CrystEngComm 2009, 11, 2797-2803.

(25) Ni, W.; Kou, X.; Yang, Z.; Wang, J. Tailoring longitudinal surface plasmon wavelengths, scattering and absorption cross sections of gold nanorods. ACS Nano 2008, 2, 677-686.
(26) Sugasaka, K.; Fujii, A. Studies on the preparation of cuprousoxide.VIII. A spectrophotometric study of halogenocopper (I) complexes in aqueous $5 \mathrm{M} \mathrm{NaClO}_{4}$ solutions. Bull. Chem. Soc. Jpn. 1980, 53, 2514-2519.

(27) Rodriguez-Fernandez, J.; Perez-Juste, J.; Mulvaney, P.; LizMarzan, L. M. Spatially-directed oxidation of gold nanoparticles by $\mathrm{Au}(\mathrm{III})$-CTAB complexes. J. Phys. Chem. B 2005, 109, 14257-14261.

(28) Zhou, Y.; Wang, S.; Zhang, K.; Jiang, X. Visual detection of copper(II) by azide- and alkyne-functionalized gold nanoparticles using click chemistry. Angew. Chem., Int. Ed. 2008, 47, 7454-7456.

(29) Lima, G. F.; Ohara, M. O.; Clausen, D. N.; Nascimento, D. R.; Ribeiro, E. S.; Segatelli, M. G.; Bezerra, M. A.; Tarley, C. R. T. Flow injection on-line minicolumn preconcentration and determination of trace copper ions using an alumina/titanium oxide grafted silica matrix and FAAS. Microchim. Acta. 2012, 178, 61-70.

(30) Kumar, B. N.; Ramana, D. K.; Harinath, Y.; Seshaiah, K.; Wang, M. C. Separation and preconcentration of $\mathrm{Cd}(\mathrm{II}), \mathrm{Cu}(\mathrm{II}), \mathrm{Ni}(\mathrm{II})$, and $\mathrm{Pb}(\mathrm{II})$ in water and food samples using Amberlite XAD-2 functionalized with 3-(2-nitrophenyl)-1H-1,2,4-triazole-5(4H)-thione and determination by inductively coupled plasma-atomic emission spectrometry. $J$. Agric. Food. Chem. 2011, 59, 11352-11358.

(31) Dai, B.; Cao, M.; Fang, G.; Liu, B.; Dong, X.; Pan, M.; Wang, S. Schiff base-chitosan grafted multiwalled carbon nanotubes as a novel solid-phase extraction adsorbent for determination of heavy metal by ICP-MS. J. Hazard. Mater. 2012, 219-220, 103-110.

(32) Jena, B. K.; Raj, C. R. Gold nanoelectrode ensembles for the simultaneous electrochemical detection of ultratrace arsenic, mercury, and copper. Anal. Chem. 2008, 80, 4836-4844.

(33) Salaun, P.; van den Berg, C. M. Voltammetric detection of mercury and copper in seawater using a gold microwire electrode. Anal. Chem. 2006, 78, 5052-5060.

(34) Shervedani, R. K.; Mozaffari, S. A. Copper(II) nanosensor based on a gold cysteamine self-assembled monolayer functionalized with salicylaldehyde. Anal. Chem. 2006, 78, 4957-4963.

(35) Liu, A. C.; Chen, D. C.; Lin, C. C.; Chou, H. H.; Chen, C. H. Application of cysteine monolayers for electrochemical determination of sub-ppb copper(II). Anal. Chem. 1999, 71, 1549-1552.

(36) Cheng, C. M.; Martinez, A. W.; Gong, J.; Mace, C. R.; Phillips, S. T.; Carrilho, E.; Mirica, K. A.; Whitesides, G. M. Paper-based ELISA. Angew. Chem., Int. Ed. 2010, 49, 4771-4774.

(37) Li, J.; Yao, J.; Zhong, W. Membrane blotting for rapid detection of mercury(II) in water. Chem. Commun. 2009, 4962-4964.

(38) Gu, Z.; Zhao, M.; Sheng, Y.; Bentolila, L. A.; Tang, Y. Detection of mercury ion by infrared fluorescent protein and its hydrogel-based paper assay. Anal. Chem. 2011, 83, 2324-2329. 